\title{
Prognostic effect of increased left ventricular wall thickness in severe aortic stenosis
}

\author{
Kyungil Park, Tae-Ho Park ${ }^{*}$ D, Yoon-Seong Jo, Young-Rak Cho, Jong-Sung Park, Moo-Hyun Kim and \\ Young-Dae Kim
}

\begin{abstract}
Background: It is unclear whether increased left ventricular (LV) thickness is associated with worse clinical outcomes in severe aortic stenosis (AS). The aim of this study was to determine the effect of increased LV wall thickness (LVWT) on major clinical outcomes in patients with severe AS.

Methods and results: This study included 290 severe AS patients (mean age 69.4 \pm 11.0 years; 136 females) between January 2008 and December 2018. For outcome assessment, the endpoint was defined as death from all causes, cardiovascular death, and the aortic valve replacement (AVR) surgery rate. During follow-up (48.7 \pm 39.0 months), 157 patients had AVR, 43 patients died, and 28 patients died from cardiovascular causes. Patients with increased LVWT underwent AVR surgery much more than those without LVWT (60.0\% vs. 39.0\%, $p<0.001)$. Furthermore, in patients with increased LWWT, the all-cause and cardiovascular death rates were significantly lower in the AVR group than in the non-AVR group (8.8\% vs. $27.3 \%, p<0.001,4.8 \%$, vs. $21.0 \%, p<0.001)$. Multivariate analysis revealed that increased LWWT, age, dyspnea, and AVR surgery were significantly correlated with cardiovascular death.

Conclusions: In patients with severe AS, increased LWWT was associated with a higher AVR surgery rate and an increased rate of cardiovascular death independent of other well-known prognostic variates. Thus, these findings suggest that increased LWWT might be used as a potential prognostic factor in severe AS patients.
\end{abstract}

Keywords: Aortic stenosis, Left ventricular hypertrophy, Echocardiography

\section{Background}

Left ventricular hypertrophy (LVH) is known as an adverse clinical factor in cardiovascular disease [1-4]. LVH in patients with aortic stenosis (AS) is characterized by increased left ventricular mass (LVM), which is the main compensatory mechanism to reduce systolic wall stress and preserve cardiac output. Although the development of LVH appears to be a beneficial adaptation in the early

\footnotetext{
* Correspondence: thpark65@dau.ac.kr

Division of Cardiology, Department of Internal Medicine, Dong-A University Hospital, Daeshingongwon-Ro 26, Seo-gu, Busan 602-715, Republic of Korea
}

stage of AS, decompensation occurs in the late stage of AS due to myocardial fibrosis. LVH is common in patients with severe AS and severe LVH is associated with an increased risk of postoperative mortality after aortic valve replacement (AVR) [5]. According to previous studies, the onset of dyspnea, angina, or syncope symptoms was an indicator of impending death in patients with AS, whereas the outcome in asymptomatic AS patients was considered benign [6]. For severe AS patients, recent guidelines assigned a Class I indication for AVR to patients with symptoms, and for those without symptoms who had systolic dysfunction or another

(C) The Author(s). 2021 Open Access This article is licensed under a Creative Commons Attribution 4.0 International License, which permits use, sharing, adaptation, distribution and reproduction in any medium or format, as long as you give appropriate credit to the original author(s) and the source, provide a link to the Creative Commons licence, and indicate if changes were made. The images or other third party material in this article are included in the article's Creative Commons licence, unless indicated otherwise in a credit line to the material. If material is not included in the article's Creative Commons licence and your intended use is not permitted by statutory regulation or exceeds the permitted use, you will need to obtain permission directly from the copyright holder. To view a copy of this licence, visit http://creativecommons.org/licenses/by/4.0/ The Creative Commons Public Domain Dedication waiver (http://creativecommons.org/publicdomain/zero/1.0/) applies to the data made available in this article, unless otherwise stated in a credit line to the data. 
cardiac surgery $[7,8]$. Progression of LVH in patients with AS may predate onset of symptoms and excessive LVH is associated with adverse outcome even in asymptomatic severe AS patients [9]. However, it is not included in the current indications of AVR [8]. Thus, we aimed to examine the association of the presence of $\mathrm{LVH}$ determined by preoperative echocardiography with clinical outcomes in severe AS patients.

\section{Methods}

\section{Patient selection}

From January 2008 to December 2018, all echocardiographic studies performed at Dong-A University Hospital were reviewed to identify severe native AS patients. A total of 290 patients were enrolled in this study. The data collection finished in December 2019 for the evaluation of AVR and death. The clinical characteristics and laboratory values of the patients were extracted from the electronic medical records. The clinical data included age, gender, height, weight, body surface area (BSA), body mass index (BMI), and blood pressure (BP). The symptoms were defined as the presence of angina, syncope, or dyspnea NYHA class $\geq$ II. Coronary artery disease (CAD) was defined by $>70 \%$ luminal reduction in major coronary arteries. The incidence of AVR, death from all causes, and cardiovascular death were compared between patients with increased left ventricular wall thickness (LVWT) and normal LVWT during the follow-up period. This retrospective study was approved by the Institutional Review Board of Dong-A University Hospital.

\section{Echocardiography}

Two-dimensional and Doppler examinations were performed using a commercially available echocardiographic system (Sonos 7500 or IE33; Philips Medical Systems) equipped with a $2.5-\mathrm{MHz}$ transducer. The LV end-diastolic dimension (LVEDD), LV end-systolic dimension (LVESD), interventricular septum (IVS), and posterior wall thickness (PWT) were measured, and LV ejection fraction (LVEF) was assessed using modified Simpson method. The LVM and LVM index (LVMI) were calculated from the parasternal M-mode measurements using validated formula. The left atrial (LA) volume was measured using the biplane Simpson method at end-systole from apical 4- and 2-chamber views. The LA volume index (LAVI) was determined as the LA volume divided by the body surface area [7]. Increased LVWT was defined as IVS $>1.0 \mathrm{~cm}$ or PWT $>1.0 \mathrm{~cm}$ [7]. Calculation of the relative wall thickness (RWT) with the formula $(2 \times \mathrm{PWT}) /(\mathrm{LVEDD})$ permits four patterns of LVH: 1) concentric hypertrophy (increased LVM with RWT > 0.42), 2) eccentric hypertrophy (increased LVM with RWT $\leq 0.42$ ), 3) concentric remodeling (normal LVM with RWT >0.42), and 4) normal geometry (normal LVM with RWT $\leq 0.42$ ) [10]. Increased LVM was defined as LVMI $>95 \mathrm{~g} / \mathrm{m}^{2}$ in women and $>115 \mathrm{~g} /$ $\mathrm{m}^{2}$ in men [11]. Continuous wave-Doppler was used to assess the peak aortic velocity and the mean PG. AVA was determined using the continuity equation. Severe native AS was defined as the presence of at least one of the following criteria: peak aortic velocity $>4 \mathrm{~m} / \mathrm{s}$, mean pressure gradient $(\mathrm{PG})>40 \mathrm{mmHg}$, aortic valve area (AVA) $<1 \mathrm{~cm}^{2}$, or indexed AVA (AVAI) $<0.6 \mathrm{~cm}^{2} / \mathrm{m}^{2}$ [12]. Grading of the severity of AR (aortic regurgitation) was based on the ACC/AHA guidelines [12].

\section{Statistical analysis}

Continuous variables are presented as the mean \pm SD. Differences between two groups were compared with t-test. Categorical variables are presented as numbers with percentages and were compared with the chi-squared test. To find out the independent risk factors for cardiovascular death in severe AS, logistic regression analysis was performed. Variables with $p$-values of 0.2 in univariate analyses were included in multivariate analysis. A $P<0.05$ was regarded as the statistical significance in all tests. All analyses were conducted using SPSS version 20.0 (SPSS, Chicago, IL, USA).

\section{Results}

Compared to patients with normal LVWT, patients with increased LVWT showed higher number hypertension and dyspnea, respectively, and a higher mean NYHA class at baseline (Table 1). During follow-up (48.7 \pm 39.0 months), a total of 157 patients had AVR and 43 patients died, 28 from cardiovascular causes. Thirty-two patients with normal LVWT (39.0\%) underwent AVR, whereas AVR was performed in 125 patients with increased LVWT $(60.0 \%)(p<0.001)$. Although the allcause death rate was not significantly different between the normal LVWT and the increased LVWT groups (9.8\% vs. $16.8 \%, p=0.127$ ), the cardiovascular death rate was significantly higher in patients with increased LVWT than in those with normal LVWT $(12.0 \%$ vs. $3.7 \%, p=0.030$, Table 1). Subgroup analysis of the death rate according to AVR surgery showed that the all-cause death rate of patients with normal LVWT was similar between the patients without and with AVR $(5 / 50,10.0 \%$ vs. $3 / 32,9.4 \%, p=0.926$ ). However, the all-cause death rate in patients with increased LVWT was significantly lower in the AVR group than in the non-AVR group $(11 / 125,8.8 \%$ vs. $24 / 83,28.9 \%, p<0.001$, Fig. 1a). Likewise, the cardiovascular death rate in the patients with increased LVWT was significantly lower in the AVR group than in the non-AVR group $(6 / 125,4.8 \%$ vs. $19 /$ $83,22.9 \%, p<0.001$, Fig. 1b). Coronary angiography was done in 147 patients (50.7\%). The prevalence of CAD in 
Table 1 Clinical characteristics

\begin{tabular}{llll}
\hline & Normal thickness $(\boldsymbol{n}=\mathbf{8 2})$ & Increased thickness $(\boldsymbol{n}=\mathbf{2 0 8})$ & $\boldsymbol{p}$ value \\
\hline Age (years) & $69.8 \pm 11.3$ & $69.3 \pm 10.9$ & 0.707 \\
Female, $\mathrm{n}(\%)$ & $36(43.9 \%)$ & $100(48.1 \%)$ & 0.523 \\
Body surface area $\left(\mathrm{m}^{2}\right)$ & $1.61 \pm 0.15$ & $1.62 \pm 0.16$ & 0.497 \\
Body mass index $\left(\mathrm{kg} / \mathrm{m}^{2}\right)$ & $23.1 \pm 3.1$ & $23.3 \pm 3.0$ & 0.790 \\
Hypertension, $\mathrm{n}(\%)$ & $29(35.4 \%)$ & $102(49.3 \%)$ & 0.032 \\
Diabetes mellitus, $\mathrm{n}(\%)$ & $23(28.0 \%)$ & $63(30.3 \%)$ & 0.707 \\
NYHA class & $2.0 \pm 0.9$ & $2.3 \pm 0.9$ & 0.030 \\
Dyspnea, $\mathrm{n}(\%)$ & $50(61.0 \%)$ & $154(74.0 \%)$ & 0.028 \\
Angina, $\mathrm{n}(\%)$ & $26(31.7 \%)$ & $75(36.1 \%)$ & 0.484 \\
Syncope, $\mathrm{n}(\%)$ & $3(3.7 \%)$ & $18(8.7 \%)$ & 0.139 \\
Serum creatinine (mg/dL) & $1.1 \pm 0.9$ & $1.3 \pm 1.1$ & 0.404 \\
AVR, $\mathrm{n}(\%)$ & $32(39.0 \%)$ & $125(60.1 \%)$ & 0.001 \\
HF hospitalization, $\mathrm{n}(\%)$ & $25(30.5 \%)$ & $61(29.3 \%)$ & 0.845 \\
Total death, $\mathrm{n}(\%)$ & $8(9.8 \%)$ & $35(16.8 \%)$ & 0.127 \\
Cardiovascular death, $\mathrm{n}(\%)$ & $3(3.7 \%)$ & $25(12.0 \%)$ & 0.030 \\
Antihypertensive drugs, $\mathrm{n}(\%)$ & $40(48.8 \%)$ & $140(67.3 \%)$ & 0.003 \\
BNP (pg/mL) & $834.9 \pm 1169.5$ & $915.9 \pm 1006.6$ & 0.672 \\
\hline
\end{tabular}

Values are mean \pm SD or $\mathrm{n}(\%)$. NYHA New York Heart Association; AVR aortic valve replacement; HF heart failure

increased LVWT groups was not significantly different from that of normal LVWT ( $44.2 \%$ vs. $41.9 \%, p=0.792)$.

\section{Echocardiography}

Compared to the group with normal LVWT, the increased LVWT group showed significantly higher IVS, PWT, LVM, and LVMI and significantly lower mitral E.
The AV peak pressure gradient (PG) and the mean PG were significantly higher in the group with increased LVWT than in the group with normal LVWT. AVA and AVAI were significantly smaller in the group with increased LVWT than in the group with normal LVWT (Table 2). Using the four categories of LV remodeling patterns, 177 patients (61.0\%) had concentric

\section{A}

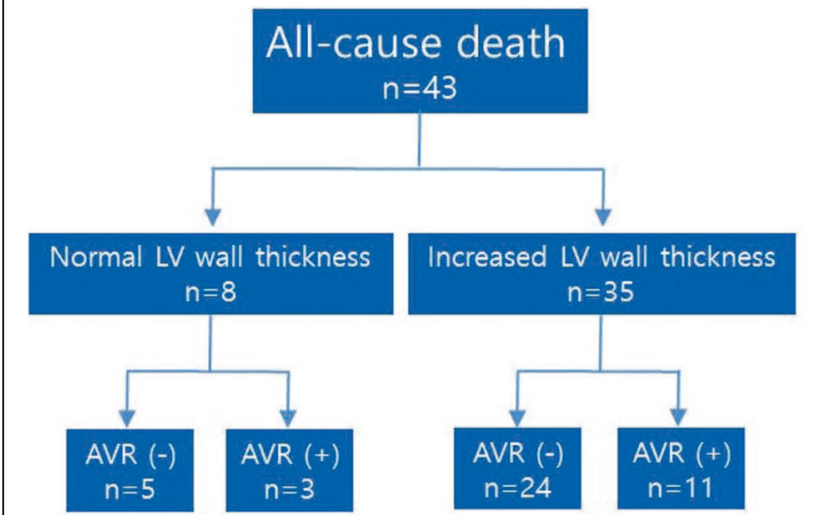

B

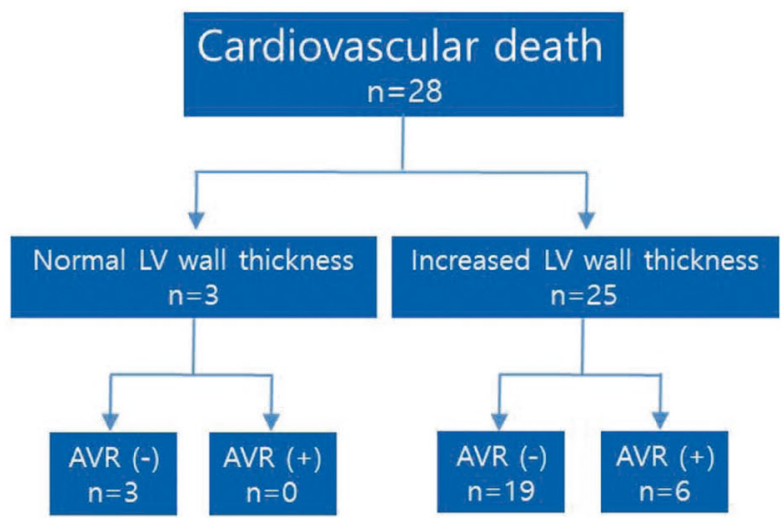

Fig. 1 Mortality in severe AS. During a mean follow-up of $48.7 \pm 39.0$ months, a total of 43 patients died, 28 from cardiovascular causes. The allcause death rate of the patients with normal LWWT was similar between the AVR and non-AVR groups $(P=.926, \mathbf{a})$. However, the all-cause death rate in patients with increased LWWT was significantly lower in the AVR group $(n=11)$ than in the non-AVR group $(n=24)(P<.001$, a). There were three cardiovascular deaths in the non-AVR group and 0 in the AVR group in patients with normal LWWT (b). The cardiovascular death rate in patients with increased LVWT was significantly lower in the AVR group $(n=6)$ than in the non-AVR group $(n=19)(P<.001$, b). LWWT, left ventricular wall thickness 
Table 2 Echocardiographic data

\begin{tabular}{|c|c|c|c|}
\hline & Normal thickness $(n=82)$ & Increased thickness $(n=208)$ & $p$ value \\
\hline LVEDD (mm) & $50.9 \pm 6.5$ & $49.6 \pm 5.8$ & 0.425 \\
\hline $\operatorname{LVESD}(\mathrm{mm})$ & $34.2 \pm 8.2$ & $33.3 \pm 8.3$ & 0.699 \\
\hline LVEF (\%) & $57.6 \pm 10.4$ & $57.8 \pm 11.3$ & 0.786 \\
\hline IVS (mm) & $9.1 \pm 1.0$ & $12.2 \pm 1.7$ & $<0.001$ \\
\hline PWT (mm) & $9.3 \pm 1.0$ & $12.4 \pm 1.7$ & $<0.001$ \\
\hline LVM (g) & $169.4 \pm 41.4$ & $241.1 \pm 56.9$ & $<0.001$ \\
\hline LVMI $\left(\mathrm{g} / \mathrm{m}^{2}\right)$ & $104.8 \pm 23.7$ & $147.6 \pm 34.0$ & $<0.001$ \\
\hline LAV (ml) & $95.7 \pm 59.1$ & $84.9 \pm 33.2$ & 0.938 \\
\hline LAVI $\left(\mathrm{ml} / \mathrm{g}^{2}\right)$ & $59.9 \pm 37.0$ & $52.8 \pm 21.6$ & 0.830 \\
\hline Mitral E (cm/s) & $112.2 \pm 48.0$ & $90.9 \pm 39.1$ & $<0.001$ \\
\hline Mitral E/A & $1.0 \pm 0.5$ & $0.9 \pm 0.6$ & 0.220 \\
\hline$E / e^{\prime}$ & $19.5 \pm 10.7$ & $18.1 \pm 9.0$ & 0.551 \\
\hline Peak velocity (m/s) & $4.3 \pm 0.4$ & $4.8 \pm 0.7$ & $<0.001$ \\
\hline Mean PG $(\mathrm{mmHg})$ & $42.5 \pm 9.7$ & $55.2 \pm 17.8$ & $<0.001$ \\
\hline $\operatorname{AVA}\left(\mathrm{cm}^{2}\right)$ & $0.8 \pm 0.2$ & $0.7 \pm 0.2$ & $<0.001$ \\
\hline $\operatorname{AVAl}\left(\mathrm{cm}^{2} / \mathrm{m}^{2}\right)$ & $0.5 \pm 0.1$ & $0.4 \pm 0.1$ & $<0.001$ \\
\hline $\mathrm{BAV}, \mathrm{n}(\%)$ & $11(13.4 \%)$ & $37(17.8 \%)$ & 0.367 \\
\hline Significant AR & $11(13.4 \%)$ & $26(12.5 \%)$ & 0.833 \\
\hline Concentric LVH, n (\%) & $10(12.2 \%)$ & $172(82.7 \%)$ & $<0.001$ \\
\hline Eccentric LVH, n (\%) & $31(37.8 \%)$ & $28(13.5 \%)$ & $<0.001$ \\
\hline Concentric remodeling, n (\%) & $6(7.3 \%)$ & $8(0.4 \%)$ & 0.214 \\
\hline Normal geometry, n (\%) & 35 (42.7\%) & 0 & \\
\hline
\end{tabular}

Values are mean \pm SD. $L V E D D$, left ventricular end diastolic dimension; LVESD left ventricular end systolic dimension; $L V E F$ left ventricular ejection fraction; IVS interventricular septum; PWT posterior wall thickness; $L V M$ left ventricular mass; $L V M I$ left ventricular mass index; $L A V$ left atrial volume; $L A V I$ left atrial volume index; PG pressure gradient; $A V A$ aortic valve area; $A V A I$ aortic valve area index; $B A V$ bicuspid aortic valve; $A R$ aortic regurgitation; $L V H$ left ventricular hypertrophy

hypertrophy, 60 patients $(20.7 \%)$ had eccentric hypertrophy, 39 patients $(13.4 \%)$ had a normal pattern, and 14 patients $(4.8 \%)$ had concentric remodeling. The 42 patients (14.5\%) included 12 patients with asymptomatic LV dysfunction (LVEF < 50\%) at the time of diagnosis. AVR surgery reduced the mortality in those patients, but it was not statistically significant, irrespective of the patient symptoms $(5 / 29,17.2 \%$ vs. $3 / 13,23.1 \%, p=0.66$, Fig. 2).

\section{Non-AVR versus AVR}

Table 3 shows a comparison of the major clinical variables between the non-AVR and AVR groups. Symptoms (especially, dyspnea) were more common in the AVR group. However, LVEF, which is a major clinical indicator for AVR surgery, was not significantly different between the two groups. The age was younger and the LVWT was thicker in AVR group, both with statistical significance.

\section{Multivariate analysis}

Table 4 shows the results of multivariate regression analysis for cardiovascular death. Multivariate regression analysis revealed that increased LVWT $(\mathrm{OR}=4.01,95 \% \mathrm{CI}: 1.16-10.68, p=0.028)$, age $(\mathrm{OR}=$ 1.05, CI: $1.04-1.15, p=0.034)$, dyspnea $(\mathrm{OR}=4.82$, CI: $1.23-11.51, p=0.040)$, AVR surgery $(\mathrm{OR}=0.10, \mathrm{CI}$ : $0.04-0.49, p<0.001)$, and CAD (OR $=4.26, \mathrm{CI}: 1.21-$ 14.94, $p=0.024$ ) were independent predictors. However, the LVEF was not a significant risk factor for cardiovascular death $(p=0.285)$.

\section{Discussion}

The major findings of the present study were as follows: (i) increased LVWT was associated with a higher rate of AVR surgery, (ii) In patients with increased LVWT, the all-cause and cardiovascular death rates were both significantly lower in the AVR group than in the non-AVR group, and (iii) Increased LVWT was an independent predictor for cardiovascular death in patients with severe native AS.

Although the presence of extreme LVH in severe AS indicates poor prognosis, current guidelines do not consider $\mathrm{LVH}$ an indication for surgical replacement in patients with AS [13]. The indications for AVR are primarily based on the presence of clinical symptoms. 


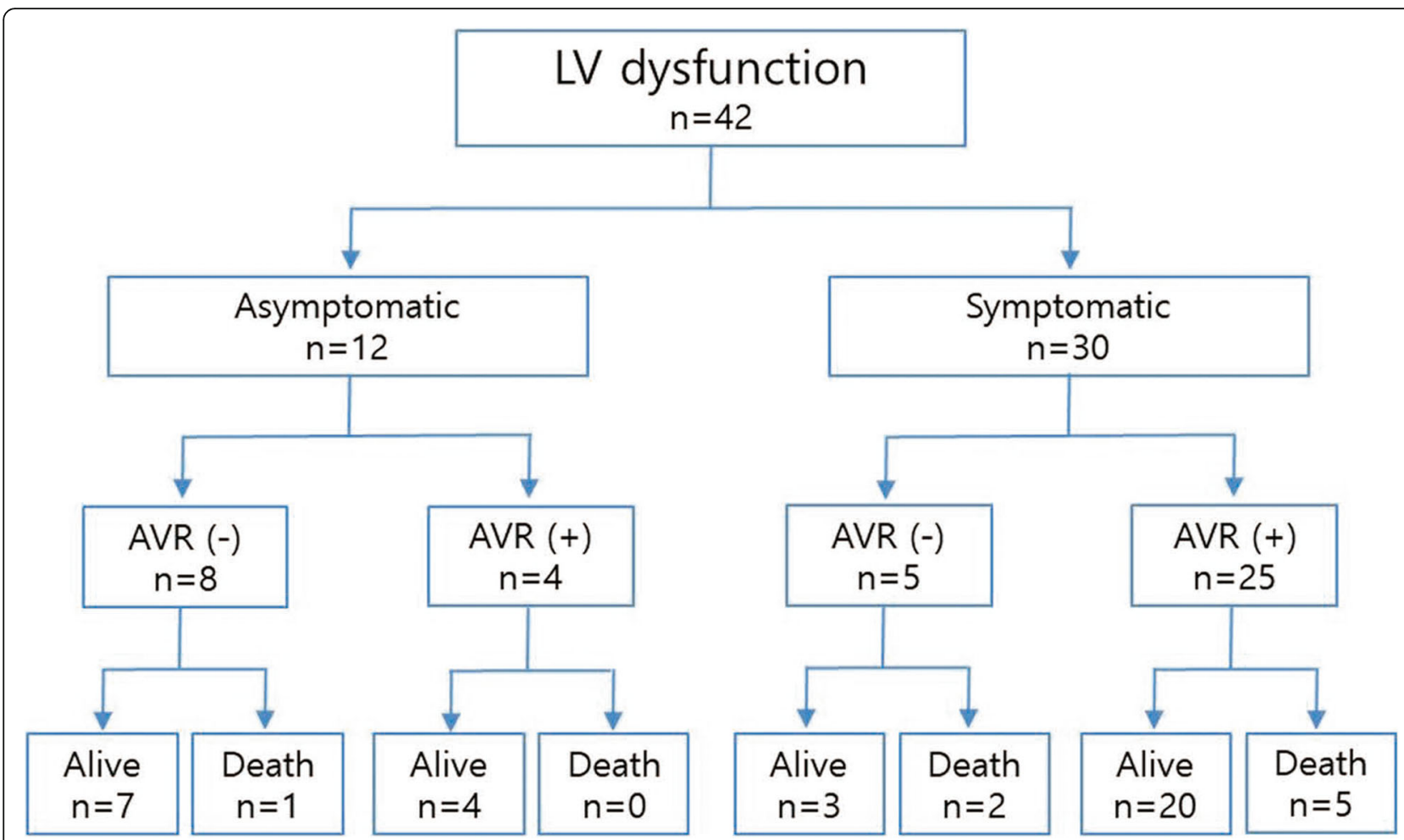

Fig. 2 Patients with severe AS and LVEF < 50\%. In our study, a total of 42 patients (14.5\%) had an LVEF < 50\%. During the mean follow-up of $48.7 \pm 39.0$ months, 29 patients (69.0\%) underwent AVR surgery and 13 patients did not. Most patients with symptomatic LV dysfunction underwent AVR (83.3\%), whereas only four patients with asymptomatic LV dysfunction underwent AVR and all were alive after AVR

However, the clinical symptoms of patients with severe AS are often difficult to differentiate from the symptoms of comorbid diseases, such as lung disease or coronary artery disease, in clinical practice. A few studies of severe AS have focused on the prognostic outcome of patients with higher LV mass or LVWT. In patients with severe AS, preoperative concentric LVH was associated with increased mortality after AVR [5]. Higher LV mass was related with worse clinical outcomes after transcatheter AVR in severe symptomatic AS [14]. In a prospective study, increased LVMI was independently related with increased cardiovascular morbidity and mortality in AS patients [15]. In addition, increased cardiovascular mortality and morbidity have been reported for asymptomatic patients with severe AS and excessive LVH [8]. Thus, we believe that increased LVWT could be an

Table 3 A comparison of clinical variables in patients with nonAVR versus AVR groups

\begin{tabular}{llll}
\hline & non-AVR $(\boldsymbol{n}=\mathbf{1 3 3})$ & AVR $(\boldsymbol{n}=\mathbf{1 5 7})$ & $\boldsymbol{p}$ value \\
\hline Symptoms, $\mathrm{n}(\%)$ & $72(54.1 \%)$ & $117(74.5 \%)$ & $<0.001$ \\
LVEF (\%) & $58.7 \pm 10.8$ & $56.9 \pm 11.2$ & 0.125 \\
Age (years) & $72.6 \pm 11.1$ & $66.7 \pm 10.2$ & $<0.001$ \\
LWWT, n (\%) & $83(62.4 \%)$ & $125(79.6 \%)$ & 0.001 \\
\hline
\end{tabular}

Values are mean \pm SD or $\mathrm{n}(\%)$. LVEF left ventricular ejection fraction; $L V$ left ventricle; $L V W T$ left ventricular wall thickness important prognostic factor in severe AS, regardless of symptoms. Although LVH in severe AS is a compensatory phenomenon to reduce wall stress and maintain cardiac output [16], it eventually causes ischemia, fibrosis, and myocardial dysfunction [17, 18]. Myocardial fibrosis independently predicts risk of mortality in patients with moderate to severe AS [19].

\section{Increased LVWT and AVR}

Because clinical decisions should be based on the risk of mortality, AVR might not a suitable endpoint in conservatively treated patients with severe AS. However, AVR is also the most important decision in the course of treatment for severe AS from a doctor's point of view. In

Table 4 Multivariate analysis for cardiovascular death

\begin{tabular}{lll}
\hline & OR & $\boldsymbol{p}$ value \\
\hline Increased LWWT & $4.01(1.16-10.68)$ & 0.028 \\
Age & $1.05(1.04-1.15)$ & 0.034 \\
Dyspnea & $4.82(1.23-11.51)$ & 0.040 \\
AVR & $0.10(0.04-0.49)$ & $<0.001$ \\
CAD & $4.26(1.21-14.94)$ & 0.024 \\
LVEF & $1.96(0.51-4.82)$ & 0.285 \\
\hline
\end{tabular}

$L V$ left ventricle; $A V R$ aortic valve replacement; $L V E F$ left ventricular ejection fraction; $L V W T$ left ventricular wall thickness 
our study, the main causes of AVR were the development of symptoms $(92 / 157,58.6 \%)$ and LV dysfunction (29/157, 18.5\%). Although LV hypertrophy was not considered a risk factor at the time of AVR, this retrospective study showed that patients with increased LVWT underwent AVR much more frequently than those without LVWT $(60.1 \%$ vs. $39.0 \%, p=0.001$, Table 1$)$. Furthermore, the cardiovascular death rate in patients with increased LVWT was significantly lower in the AVR group than in the non-AVR group (Fig. 2b). These results imply that LV hypertrophy may be an important risk factor in AVR decisions.

\section{Mortality}

The multivariate regression analysis in this study showed that increased LVWT was independently correlated with cardiovascular death in patients with severe AS. In this study, 108 patients (108/208, 51.9\%) with increased LVWT had no or mild symptoms. In addition, 36 patients $(36 / 125,28.8 \%)$ with increased LVWT who underwent AVR had no or mild symptoms. This may imply that symptom-based decisions for interventions in severe AS might miss a chance for surgery in patients (about 30\%) with no significant symptoms. Thus, LVH could be used as a more sensitive marker than symptomatic criteria for AS surgery decisions. Previous studies reported that LVH was associated with an increased rate of cardiovascular events in severe AS independent of other prognostic covariates, even in asymptomatic patients $[14,15,20$, 21]. Recently, Kang reported that the incidence of cardiovascular death was significantly lower in those who underwent early AVR surgery than asymptomatic patients with very severe AS who received conservative care [22]. In our study, patients with increased LVWT had a 4.45 -fold higher risk of cardiovascular death than those with normal LVWT. Interestingly, the predictors of cardiovascular death in this study were age, symptoms, AVR surgery, CAD, and increased LVWT, not LVEF. LV dysfunction is a wellknown strong predictor of worse long-term survival, but our results did not agree with those of previous studies [23]. Although LV dysfunction caused by severe AS itself is a very important risk factor for cardiovascular death and a class I indicator for AVR surgery, LV dysfunction can develop from other combined valve diseases, or post-myocardial infarction. In our study, the LVEF was not significantly different between the AVR and non-AVR group. Additionally, among 42 patients with systolic dysfunction, 12 patients were asymptomatic, and only four patients $(4 / 125,3.2 \%)$ had AVR surgery attributable to LV dysfunction itself (Fig. 2). Among the 29 deaths in non-AVR patients, 6 deaths ( 2 cardiac and 4 non- cardiac) were observed even in patients with normal systolic function. These are asymptomatic but had increased LV wall thickness. This implies that LVEF would not be a perfect indicator of AVR surgery in real practice. In contrast, increased LVWT was more common in the AVR group and showed statistical significance as a variable correlated with cardiovascular death. LVH as a factor modifying the timing for AVR is not a new concept. Previous reports clearly demonstrated associations between pre-operative $\mathrm{LVH}$ and post-AVR mortality [24, 25]. Thus, it might be a good additional index for AVR surgery decisions in patients with severe AS, in addition to symptoms. Bicuspid aortic valve (BAV) is associated with aortic root dilation and progressive dilatation of ascending aorta was reported [26, 27]. By contrast, others demonstrated that long-term clinical outcomes and aortic root dilatation were similar between BAV and tricuspid AV (TAV) $[28,29]$. We examined whether BAV can be other prognostic factors in severe AS. However, mortality of patients with BAV were similar with those of TAV patients $(10.4 \%$ vs. $15.7 \%, p=0.818)$. Honda et al. have reported that concomitant AR in severe AS patients had significantly worse clinical outcomes [30]. In present study, significant AR was observed in $12.7 \%$ of severe AS patients and mortality of patients with concomitant significant AR was not significantly different from those of patients without concomitant significant AR $(11.6 \%$ vs. $12.4 \%, p=0.661)$. The prevalence of $C A D$ in death patients was significantly higher than that in survived patients $(66.7 \%$ vs. $39.0 \%$, $p=0.012$ ). Likewise, mortality of CAD patients was significantly higher than that of patients without CAD in severe AS $(25.0 \%$ vs. 9.6\%, $p=0.012)$. This study had limitations. First, because this was a retrospective study, the clinical data may be incomplete. Second, the follow-up period was clearly too short and the absolute number of patients was too small to have strong statistical power. Third, LVH may be a consequence or reflection of the AS severity, not be the independent factor, because it was obtained by narrowrange analysis of LV wall thickness. Forth, we tried to incorporate $\mathrm{LVH}$ as an indication for AVR with classic symptoms and LV dysfunction, but this approach is incomplete comparison, because considerable patients with symptoms or LV dysfunction did not have AVR due to their very old age and poor health condition.

\section{Conclusions}

In conclusion, increased LVWT was an independent predictor of cardiovascular death. Thus, AVR should be strongly considered in all AS patients with increased LVWT, even in asymptomatic patients. 


\section{Acknowledgements}

Not applicable.

\section{Authors' contributions}

Design of the study: TH Park. Drafting of article: K Park, TH Park, Acquisition and analysis of data: YS Jo, YR Cho, JS Park, MH Kim, YD Kim. All authors have approved the final article to be submitted.

\section{Funding}

This study was supported by the Dong-A University Research Fund.

\section{Availability of data and materials}

All data generated or analysed during this study are included in this published article.

\section{Ethics approval and consent to participate}

The study protocol was approved by the institutional review board of our center (IRB No. 20-073).

\section{Consent for publication}

Not applicable.

\section{Competing interests}

The authors declare that they have no competing interests.

Received: 7 August 2020 Accepted: 16 December 2020

Published online: 06 January 2021

\section{References}

1. Levy D, Garrison RJ, Savage DD, Kannel WB, Castelli WP. Prognostic implications of echocardiographically determined left ventricular mass in the Framingham Heart Study. N Engl J Med. 1990;322:1561-6.

2. Casale PN, Devereux RB, Milner M, Harshfield GA, Pickering TG, Laragh JH. Value of echocardiographic left ventricular mass in predicting cardiovascular morbid events in hypertensive men. Ann Intern Med. 1986;105:173-8.

3. Cooper RS, Simmons BE, Castaner A, Santhanam V, Ghali J, Mar M. Left ventricular hypertrophy is associated with worse survival independent of ventricular function and number of coronary arteries severely narrowed. Am J Cardiol. 1990;65:441-5.

4. Liao Y, Cooper RS, McGee DL, Mensah GA, Ghali JK. The relative effects of left ventricular hypertrophy, coronary artery disease, and ventricular dysfunction on survival among black adults. JAMA. 1995;273:1592-7.

5. Duncan Al, Lowe BS, Garcia MJ, Gillinov AM, Mihaljevic T, Koch CG. Influence of concentric left ventricular remodeling on early mortality after aortic valve replacement. Ann Thorac Surg. 2008;85:2030-9.

6. Ross JE Jr. Braunwald Aortic stenosis. Circulation. 1968;(1 Suppl):61-7.

7. Lang RM, Bierig M, Devereux RB, Flachskampf FA, Foster E, Pellikka PA, et al. Recommendations for chamber quantification: a report from the American Society of Echocardiography's Guidelines and Standards Committee and the Chamber Quantification Writing Group, developed in conjunction with the European Association of Echocardiography, a branch of the European Society of Cardiology. J Am Soc Echocardiogr. 2005;18:1440-63.

8. Baumgartner H, Falk V, Bax JJ, Bonis MD, Hamm C, Holm PJ, et al. 2017 ESC/ EACTS guidelines for the management of valvular heart disease. Eur Heart $J$. 2017;38:2739-91.

9. Cioffi G, Faggiano P, Vizzardi E, Tarantini L, Cramariuc D, Gerdts E, et al. Prognostic effect of inappropriately high left ventricular mass in asymptomatic severe aortic stenosis. Heart. 2011:97:301-7.

10. Seiler C, Jenni R. Severe aortic stenosis without left ventricular hypertrophy: prevalence, predictors, and short-term follow up after aortic valve replacement. Heart. 1996;76:250-5.

11. Lang RM, Badano LP, Mor-Avi V, Afilalo J, Armstrong A, Ernande L, et al. Recommendations for cardiac chamber quantification by echocardiography in adults: an update from the American Society of Echocardiography and the European Association of Cardiovascular Imaging. J Am Soc Echocardiogr. 2015;28:1-39 e14.

12. Nishimura RA, Otto CM, Bonow RO, Carabello BA, Erwin JP 3rd, Guyton RA et al. American College of Cardiology/American Heart Association Task Force on Practice Guidelines. 2014 AHA/ACC guideline for the management of patients with valvular heart disease: a report of the American College of
Cardiology/American Heart Association Task Force on Practice Guidelines. J Am Coll Cardiol. 2014;63:e57-185.

13. Nishimura RA, Otto CM, Bonow RO, Carabello BA, Erwin JP 3rd, Fleisher LA, et al. 2017 AHA/ACC Focused Update of the 2014 AHA/ACC Guideline for the Management of Patients With Valvular Heart Disease: A Report of the American College of Cardiology/American Heart Association Task Force on Clinical Practice Guidelines. J Am Coll Cardiol. 2017;70:252-89.

14. Lindman BR, Stewart WJ, Pibarot P, Hahn RT, Otto CM, Xu K, et al. Early regression of severe left ventricular hypertrophy after trascatheter aortic valve replacement is associated with decreased hospitalizations. JACC Cardiovasc Interv. 2014;7:662-73.

15. Gerdts E, Rossebø AB, Pedersen TR, Cioffi G, Lønnebakken MT, Cramariuc D, et al. Relation of left ventricular mass to prognosis in initially asymptomatic mild to moderate aortic valve stenosis. Circ Cardiovasc Imaging. 2015;8: e003644.

16. Gaasch WH, Zile MR. Left ventricular structural remodeling in health and disease: with special emphasis on volume, mass. and geometry. J Am Coll Cardiol. 2011;58:1733-40.

17. Peterson KL, Tsuji J, Johnson A, DiDonna J, LeWinter M. Diastolic left ventricular pressure-volume and stress-strain relations in patients with valvular aortic stenosis and left ventricular hypertrophy. Circulation. 1978;58: 77-89.

18. Weidemann F, Herrmann S, Stork S, Niemann M, Frantz S, Lange V, et al. Impact of myocardial fibrosis in patients with symptomatic severe aortic stenosis. Circulation. 2009;120:577-84.

19. Dweck MR, Joshi S, Murigu T, Alpendurada F, Jabbour A, Melina G, et al. Midwall fibrosis is an independent predictor of mortality in patients with aortic stenosis. J Am Coll Cardiol. 2011;58:1271-9.

20. Orsinelli DA, Aurigemma GP, Battista S, Krendel S, Gaasch WH. Left ventricular hypertrophy and mortality after aortic valve replacement for aortic stenosis: a high risk subgroup identified by preoperative relative wall thickness. J Am Coll Cardiol. 1993;22:1679-83.

21. Mihaljevic T, Nowicki ER, Rajeswaran J, Blackstone EH, Lagazzi L, Thomas J, et al. Survival after valve replacement for aortic stenosis: implications for decision making. J Thorac Cardiovasc Surg. 2008;135:1270-8.

22. Kang DH, Park SJ, Lee SA, Lee S, Kim DH, Kim HK, et al. Early Surgery or Conservative Care for Asymptomatic Aortic Stenosis. N Engl J Med. 2020; 382:111-9.

23. Aronow WS, Ahn C, Kronzon I, Nanna M. Prognosis of congestive heart failure in patients aged $>$ or $=62$ years with unoperated severe valvular aortic stenosis. Am J Cardiol. 1993;72:846-8.

24. Davies C, Zerebiec K, Rożanowska A, Czestkowska E, Długosz D, Chyrchel B, et al. Is left ventricular hypertrophy a fiiend or foe of patients with aortic stenosis? Postepy Kardiol Interwencyjnej. 2018;14:328-37.

25. Koerber JP, Bennetts JS, Psaltis PJ. Early Valve Replacement for Severe Aortic Valve Disease: Effect on Mortality and Clinical Ramifications. J Clin Med. 2020;9:2694.

26. Borger MA, Preston M, Ivanov J, Fedak PW, Davierwala P, Armstrong S, et al. Should the ascending aorta be replaced more frequently in patients with bicuspid aortic valve disease? J Thorac Cardiovasc Surg. 2004;128:677-83.

27. Miśkowiec D, Lipiec P, Szymczyk E, Wejner-Mik P, Michalski B, Kupczyńska K, et al. Bicuspid aortic valve morphology and its impact on aortic diameters - A systematic review with meta-analysis and meta-regression. Echocardiography. 2018;35:667-77.

28. McKellar SH, Michelena HI, Li Z, Schaff HV, Sundt IIITM. Long-term risk of aortic events following aortic valve replacement in patients with bicuspid aortic valves. Am J Cardiol. 2010;106:1626-33.

29. Kim MS, Kim JH, Lee SH, Lee S, Youn YN, Yoo KJ, et al. Long-term fate of dilated ascending aorta after aortic valve replacement for bicuspid versus tricuspid aortic valve disease. Am J Cardiol. 2020;129:53-9.

30. Honda S, Kitai T, Okada Y, Tani T, Kim K, Kaji S, et al. Impact of aortic regurgitation on the prognosis of severe aortic stenosis. Heart. 2012;98: $1591-4$.

\section{Publisher's Note}

Springer Nature remains neutral with regard to jurisdictional claims in published maps and institutional affiliations. 